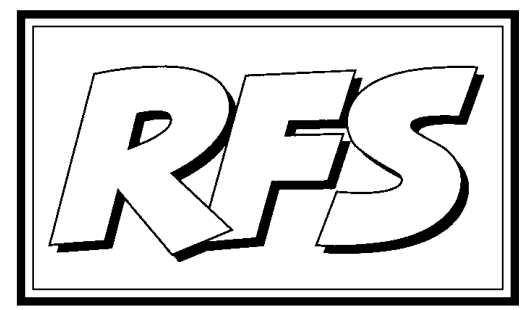

Revista de Fomento Social, 56 (2001), 343-367

\title{
La Política Agraria Común europea en un mundo globalizado ${ }^{1}$
}

Consejo de Redacción

“Entonces el Corazón del Cielo les echó un vaho sobre los ojos, los cuales se empañaron como cuando se sopla sobre la luna de un espejo. Sus ojos se velaron y sólo pudieron ver lo que estaba cerca, sólo eso era claro para ellos. Así fue destruida su sabiduría..."2

Dos son las razones inmediatas que nos llevan a tratar el presente tema en este artículo editorial. Por una parte, los cambios - relativamente pequeñosocurridos en la Política Agraria Común (PAC) de la Unión Europa (UE) con

1 Para la elaboración de este texto hemos partido de un documento más largo elaborado por el equipo de ETEA por encargo de Intermón Oxfam, en el marco de la preparación de una campaña de Oxfam Internacional encaminada a promover la introducción de criterios de justicia en las relaciones comerciales internacionales, en particular en materia de productos agrarios. Dicho texto largo será próximamente publicado en coedición por ETEA, Desclée de Brouwer e Intermón Oxfam.

2 El Popol Vuh. Las antiguas historias del Quiché. Traducidas del texto original con introducción y notas de Adrián Recinos. Ed. Universitaria Centroamericana (EDUCA). Colección Aula. Centroamérica, 1971 p. 102-103. 
motivo de la aprobación de la Agenda 2000 en la Cumbre europea de Berlín de julio de 1999, con el horizonte de un sexenio, se acercan a la mitad de su recorrido, y es el momento para proceder a lo que se suele conocer en el argot comunitario como una mid-term review, o revisión a mitad de su periodo de vigencia. Esto por lo que respecto al ámbito interior de la propia UE.

Por otro lado, de cara al exterior, si las circunstancias especiales derivadas de los trágicos atentados del 11 de septiembre no lo impiden, cuando este número esté en imprenta, del 9 al 13 de noviembre de 2001, se celebra en Doha (Qatar) la 4a Conferencia Ministerial de la Organización Mundial de Comercio; como se explica más adelante, pase lo que pase con y en esta Conferencia, uno de los temas "estrella" en general de la agenda de la OMC tiene mucho que ver con las políticas proteccionistas de la agricultura de los países de la OCDE, muy en particular de la UE.

Pero, más allá de esos motivos coyunturales, en último término lo que pretendemos en este editorial es reflexionar sobre la responsabilidad de los países europeos, miembros del reducido círculo de los ricos del Norte, en un tema que no tenemos resuel to hacia dentro y que provoca importantes negativas consecuencias hacia fuera, en particular hacia los países menos desarrollados.

\section{Los orígenes de la PAC: "en el principio no fue el mercado"}

La PAC europea no nace con una pretensión exportadora o expansionista. En sus orígenes está la necesidad de garantizar el precario abastecimiento alimenticio de la Europa de los años 50; de alguna manera fue una concesión alemana a la generosidad política con la que Francia lideró la creación primero de la CECA y luego de la CEE y el Euratom con el país que había sido su tradicional enemigo. A principios de la década de los años 60 era auténticamente revolucionaria una política de solidaridad intersectorial e internacional como la PAC, como lo fue ya entrados los años 70 la política regional europea orientada a corregir los desequilibrios en el nivel de desarrollo entre las distintas regiones europeas.

En efecto, no se puede olvidar que los objetivos previstos para la PAC en el famoso artículo 39 del Tratado de Roma, instrumentados tras la posterior conferencia de Stresa con toda una serie de reglamentos, eran los siguientes: incrementar la productividad agrícola; garantizar a la población agrícola un nivel de vida equitativo; estabilizar los mercados agrarios; garantizar la seguridad de los abastecimientos; asegurar a los consumidores suministros a 
precios razonables. Más adelante volveremos sobre estos objetivos de la PAC.

Destacamos de nuevo el hecho de que en sus orígenes la PAC no tenía la menor intención de introducir las producciones agrarias de los países de la CEE en los mercados internacionales. El objetivo programático del Tratado de Roma consistía en garantizar a los agricultores (cuyo protagonismo en el medio rural de aquel entonces era indiscutido) un nivel de vida digno; de alguna manera se establecía así la base filosófica de la protección que, a nuestro entender, trascendía las coordenadas de espacio y tiempo en que se formuló, convirtiéndose en una de las justificaciones más sólidas de la protección rural.

El sistema seguido era muy simple. Para los grandes sectores de la agricultura comunitaria (la de los países fundadores: cereales, aceite de oliva, azúcar y productos ganaderos), se aplicó una férrea protección en frontera, un régimen de precios elevados y un sistema de intervención y de almacenamiento eficaz. En aquellos sectores agrarios en que la comunidad primitiva era deficitaria (oleaginosas, tabaco, algodón, carne de ovino) se procedió a una liberalización de importaciones compaginándola con ayudas directas a productores comunitarios. Por último en los sectores de frutas, hortalizas y vino, el sistema seguido se basaba en un precio mínimo de importación (precio de referencia, para los productos procedentes de terceros países) acompañado de unos peculiares sistemas de eliminación de excedentes (destilaciones y retiradas).

\section{La crisis de la PAC: una política víctima de su propio éxito}

Víctima de su propio éxito, a partir de finales de los años 70, y sobre todo en los 80, la PAC generó una serie de efectos perversos internos (cuantiosos excedentes, elevado coste financiero, desigual distribución entre zonas y países y entre agricultores, efectos medioambientales negativos etc.) y externos (presiones sobre los mercados internacionales debido a las abundantes exportaciones subvencionadas de ciertos productos y a las fuertes restricciones a las importaciones agrarias). A mitad de la década de los 80 todo esto coincide con un grave desencuentro entre los entonces 12 países miembros con relación a la financiación de los gastos agrarios, con una disidencia británica permanente y beligerante, ya que el Reino Unido se negaba a financiar este tipo de políticas que iban en contra de su tradicional sistema basado en los "deficiency payments". Estos últimos consistían en ayudas directas a los agricultores y precios bajos a los productos; el mercado se abastecía gracias las cuantiosas importaciones de alimentos procedentes de los países de la antigua Commonwealth. 
El final de la década de los 80 coincide con la apertura de la Ronda Uruguay que introduce por primera vez el debate agrícola en el seno del GATT ${ }^{3}$. En la dialéctica negociadora, la CEE se convierte en el bloque más atacado, merced a la alianza entre Estados Unidos (que mantenía el contencioso desde hacía años) y el grupo de Cairns que logró aglutinar a una buena parte de los países exportadores perjudicados por las medidas proteccionistas europeas. Coincide este "ataque" externo en toda regla contra la PAC, con el replanteamiento interno, cuyo punto álgido puede situarse en el famoso Informe Mac Sharry y su propuesta de reforma de 1992. La propuesta fue muy mal recibida por los agricultores europeos en general, y franceses en particular, ya que el potente lobby agrario veía por primera vez en peligro su situación privilegiada.

Si algo queda claro después de los acuerdos de Marraquesh (con los que concluyó la Ronda Uruguay) es que la política agraria europea había "perdido la batalla" de la opinión pública mundial y que se encontraba fuertemente deslegitimada en particular ante los países menos desarrollados, perjudicados por el proteccionismo europeo; ello no puede hacer ignorar la hipocresía de otras áreas o países ricos exportadores -como Estados Unidos o Canadá- que encontrarán en la UE el chivo expiatorio, como si sus propias políticas ( iy no sólo agrarias!) fueran especialmente solidarias.

\section{La reforma de la PAC: del productivismo al ruralismo}

Simultáneamente se asiste en el propio seno de la UE a lo que podríamos llamar el despertar del paradigma ruralista: se trata de una corriente de pensamiento, muy potente en particular paradójicamente en Francia, pero también en otros países influencia dos por la "ola verde" de los movimientos ecologistas, especialmente Alemania y otros países de la Europa rica continental.

El énfasis por la calidad de los alimentos y de la vida en general, la creciente preocupación por la protección del medio ambiente (no olvidemos que la Cumbre de Río tiene lugar al comienzo de la década de los 90), el redescubrimiento de la multifuncionalidad de la agricultura y del territorio rural, y la aparición de políticas alternativas de desarrollo rural no enfocadas a la intensificación productiva agraria (cuyo exponente paradigmático serían los

3 Acuerdo General sobre Tarifas y Comercio, hoy Organización Mundial del Comercio (OMC). 
programas $\operatorname{LEADER}^{4}$ ) abren una brecha en la hasta ahora prácticamente monolítica política productivista europea. Las nuevas tendencias responden también al deseo de los agricultores y de los habitantes del medio rural de permanecer en su medio de origen y de vida sin sufrir merma por ello en su calidad de vida, ni sufrir agravios comparativos en su grado de desarrollo con respecto a los habitantes de las ciudades.

¿Hacia dónde se dirige esta evolución? Las sucesivas oleadas reformistas de la PAC europea, aunque muy lentamente y con fuertes inercias económicas e institucionales, están implicando cambios profundos, aunque todavía insuficientes. Ante estos cambios, son muchas las posturas que se pueden adoptar, pero sintentizando se pueden resumir en tres.

\section{Tres estrategias ante los cambios de la PAC ${ }^{5}$}

\section{a) La estrategia del status quo}

Esta postura quedó reflejada en los acuerdos de Berlín de julio de 1999, materializados en la famosa Agenda 2000. Este importante documento, cuyo horizonte se prevé hasta el año 2006, incluye numerosas modificaciones en el funcionamiento de los distintos aspectos de la Unión. Respecto al mundo rural, la Agenda 2000 introdujo lo que nosotros llamamos la reforma de la reforma de la PAC.

En cuanto al mundo rural la Agenda contiene dos pilares básicos: el sector agrario y el desarrollo rural. Hemos de señalar que la Agenda 2000 supone una continuidad en la evolución de dos aspectos que marcaron la ya vieja reforma de la PAC de 1992: a) la nueva concepción de la PAC de los años ochenta (contención de los gastos agrarios, ajuste presupuestario, protección del medio ambiente, desarrollo del mundo rural, etc.) y b) los compromisos internacionales en el seno de la entonces GATT y hoy OMC. En resumen, la agenda 2000

4 Como es sabido, LEADER viene de las iniciales de "Liaison entre activités de développement rural", y es una Iniciativa comunitaria, relativamente exitosa, consistente en la promoción de actividades multisectoriales de desarrollo endógeno -no directamenteagropecuarias-en las zonas rurales europeas.

5 En este apartado seguimos la excelente sistematización de JACQUES BERTHELot.- "Un autre modèle pour l'agriculture. L'urgente réforme des politiques européennes". Le Monde Diplomatique, avril 2001, pp. 4-5. 
continúa con la progresiva desprotección interna de los agricultores en lo que respecta a los mecanismos de intervención (precios de garantía y compra y almacenamiento de productos excedentarios) e incrementa las ayudas directas a los agricultores, desligándolas de la cantidad producida. Por otra parte, la reducción de precios a la intervención de los principales productos permitirá un acercamiento de los precios internos a los mundiales, lo que en parte permitirá igualmente un aumento de las importaciones de productos del resto del mundo a la UE al reducirse las barreras arancelarias a niveles muy pequeños.

Por todo ello puede afirmarse que, en líneas generales, la reforma de la reforma es continuista ("más de lo mismo"), es básicamente la postura oficial y no rompe con la política agraria existente, en sintonía con lo que ha sido la forma de hacer política dentro de la UE: un paso hacia adelante, aunque sea pequeño, es avanzar, aunque quizás para tamaño viaje no hagan falta estas alforjas.

¿Quiénes son sus defensores? Constituye, de alguna manera, la estrategia negociadora de la Comisión Europea ante la OMC y es la postura predominante entre los sindicatos agrarios mayoritarios, representativos de la franja de agricultores más modernos y dinámicos y con explotaciones de mayor dimensión. También de algunas empresas del complejo agroindustrial, generalmente organizadas en forma de oligopolios multinacionales.

Los principios y medidas bá sicas de esta postura se orientan a preservar el modelo agrícola europeo manteniendo la "vocación exportadora" (con producciones agroganaderas cada vez más competitivas) y la "multifuncionalidad" (orientación del medio rural a la producción de bienes y servicios no agrarios, funciones que pueden y deben ser retribuidas con ayudas públicas). Se aceptaría cambiar algunas de las medidas adoptadas en Berlín por la Agenda 2000 con el fin de "vender" la reforma ante la OMC ( por ejemplo reduciendo más de lo previsto las barreras a las importaciones y las subvenciones a las exportaciones, así como las ayudas todavía ligadas de alguna manera a las cantidades producidas). Se mantendrían, sin embargo, las ayudas directas parcialmente ligadas a la producción, ya que a pesar de no calcularse en función de las cantidades producidas, el sistema prevé que la dimensión de la explotación será el criterio básico de distribución.

Esta postura tiene algunas consecuencia s o dificultades considerables en el mismo interior de la UE. De alguna manera implica dos facetas que son parcialmente contradictorias: "vocación exportadora" ( ser más productivos en cantidad y competitivos en calidad de producciones agroganaderas) y "multi- 
funcionalidad" ( retribuir por otras funciones distintas de la producción agropecuaria) ya que la intensificación es difícilmente amistosa con el medio natural y la riqueza paisajística. No deja de ser, por tanto, un modelo productivista, eso sí, con una "pizca" de agricultura razonada y adornada por la multifuncionalidad para reducir los efectos perversos de la antigua PAC. Una dificultad añadida es que estos cambios disgustan a los sindicatos mayoritarios que los consideran demasiado revolucionarios, ya que son contrarios a sus intereses productivistas. Por otro lado, en esta postura no se presta atención a las consecuencias negativas del mantenimiento del status quo en los países del Sur: continúan las exportaciones con dumping también hacia el Sur y se siguen poniendo impedimentos a las importaciones de dichos países. En los documentos negociadores de la Comisión Europea ante la OMC no hemos encontrado la menor alusión a este problema, lo que resulta particularmente significativo.

\section{b) La estrategia del "mundial-ecologismo"}

Esta es la postura defendida por Estados Unidos, y respaldada por el grupo de países llamado de Cairns ${ }^{6}$, así como por algunas empresas agroalimentarias. También comparten esta visión: la Oficina Europea de Uniones de Consumidores y, paradójicamente, algunos partidos "verdes" y algunas ONG, que están más cerca de esta postura de lo que parecen confesar, con contradicciones internas importantes.

Esta estrategia se basa en los siguientes principios o medidas: eliminación rápida de toda protección exterior e interior a los productos agropecuarios; concesión de ayudas desligadas totalmente de la producción para retribuir lo que se ha venido en llamar "amenidades", es decir, servicios rurales tipo turismo rural, producción de paisaje, defensa del medioambiente, etc.; crítica al productivismo intensivo y a la concentración de las ayudas en los más grandes agricultores; control estricto de la contaminación producida por las prácticas agrícolas intensivas y remuneración de las funciones medioambientales de la agricultura "limpia"; alineación de los preciosinternos de los productos agrarios con los precios mundiales para acabar así con los problemas de la UE en la OMC.

6 Se trata de un grupo de países exportadores agrarios cuyo nombre proviene de la ciudad australiana de Cairns. Lo fundan en 1986 catorce países: Argentina, Australia, Brasil, Canadá, Chile, Colombia, Fiji, Hungría, Indonesia, Malasia, Filipinas, Nueva Zelanda, Thailandia, y Uruguay. Hoy está formado por 15 países. Tras su fundación han entrado la Unión Sudafricana y Paraguay y ha salido Hungría. 
Los efectos o consecuencias principales de esta estrategia son los siguientes: se consagra la tendencia a la superespecialización, sólo serán productivas y competitivas unas miles de explotaciones ultratecnificadas y de dimensiones enormes; se trata de una postura que despierta poco entusiasmo en los sindicatos agrarios europeos mayoritarios ya que reduce a la mayoría de los agricultores al papel de productores de las citadas "amenidades" lejos de su tradicional oficio de abastecedores de alimentos para la población; los defensores de esta estrategia se contradicen al pretender que sea a la vez una política más "agroalimentaria", y más "rural" o "ruralista": su principal error es la pretensión dogmática de alinear los precios internos con los mundiales (que son normalmente, no lo olvidemos, precios de excedentes, de saldos).

Además se siguen de esta postura dos corolarios muy discutibles: el problema de la incertidumbre en los precios se resolverá con contratos de futuro y con seguros contra los riesgos derivados de la total liberalización; $y$, en segundo lugar, que sería posible asegurar una renta suficiente a los agricultores con una ayuda personal y condicionada a los beneficios medioambientales producidos por cada uno.

Por otro lado, en esta postura se pretende retribuir también a los no agricultores: "paisaje sin campesinos" (paysage sans paysans). Se trata, en suma de una postura hiper-liberal, que pretende eliminar toda tentativa de controlar la producción: nada de cuota ni de controles; para eso está el mercado.

De cara a los países del Sur, esta estrategia tiene entre otros el inconveniente -coincide en esto con la primera postura de defensa del status quo- de no preocuparse prácticamente nada de los efectos externos de la nueva PAC preconizada; se adivina, por otra parte, que las exportaciones a bajo precio de productos agrarios de los países del Sur sólo beneficiarán a las multinacionales agroalimentarias; es de temer, como consecuencia, que disminuya la producción total de alimentos en los países en vías de desarrollo (PVD). La iniciativa $\mathrm{EBA}^{7}$ ("Todo salvo armas") si no es asimétrica (o sea, si no protege a las naciones más pobres de la invasión de las importaciones procedentes de los países ricos) resultaría una cínica forma de ganarse el voto de los PVD en las negociaciones de la OMC, ya que la UE exige en concreto a este grupo de países que abran sus fronteras a todos los productos europeos (no sólo agrarios) de

7 "Everything but arms", iniciativa loable, aunque incompleta, conducente a liberar de toda traba aduanera directa o indirecta a las exportaciones de los 49 países más atrasados (menos avanzados o PMA) del planeta con excepción de las armas. 
exportación. Además, las exportaciones de los productos tropicales del Sur hacia la UE se harán al precio mundial que, en algún caso como el azúcar, es inferior incluso al coste de producción.

\section{c) La estrategia campesino-ciudadana}

Los defensores de esta postura son la Coordinadora campesina europea (encabezada por el conocido agricultor francés J osé Bové, cara visible agraria del movimiento antiglobalización europeo), las asociaciones ambientalistas, ciertas ONG de solidaridad internacional, algunos partidos verdes y algunas asociaciones de consumidores más sensibles a los problemas del Sur.

Esta estrategia se basa en los siguientes principios o medidas: ante todo, reconocimiento del derecho de cada país (o grupo de países, v.g. la UE) a la soberanía alimentaria y a la autosuficiencia en alimentos básicos. Con el Foro Mundial de La Habana de 2001 sobre el tema, entendemos por soberanía alimentaria "el derecho de los pueblos a definir sus propias políticas y estrategias sustentables de producción, distribución y consumo de alimentos que garanticen el derecho a la alimentación para toda la población, con base en la pequeña y mediana producción, respetando sus propias culturas y la diversidad de los modos campesinos, pesqueros e indígenas de producción agropecuaria, de comercialización y de gestión de los espacios rurales, en los cuales la mujer desempeña un papel fundamental".

Además, se propugna la defensa a ultranza de la multifuncionalidad y la necesaria sostenibilidad ambiental de un mundo rural que sólo tendrá futuro si es multisectorial; protección frente a las importaciones con barreras de entrada tipo prélèvements ${ }^{8}$. Nótese que la propuesta de esta tercera estrategia admite estos prélèvements (hoy "condenados") por la OMC que propugna una total transformación en aranceles de las protecciones residuales, tanto en países europeos, bajo ciertas condiciones, como sobre todo en el Sur.

Asimismo, se defiende una política conducente a ligar la ganadería al suelo (con el uso de pastos), disminuyendo drásticamente la dependencia de los alimentos compuestos concentrados ( causa en último término de accidentes tan graves conmo la conocida "enfermedad de las vacas locas"). Otras propuestas

8 También llamadas "exacciones reguladoras": son unos aranceles peculiares, puesto que no se calculan sobre el valor de la mercancía importada (ad valorem), sino como diferencia entre el precio mundial y el que se considera justo a la entrada en el país importador. 
son: frenar el crecimiento de la dimensión de las explotaciones, y establecer algún tipo de precio de intervención (o de garantía), con la consiguiente constitución de stocks de seguridad, para salvaguardar la producción de los agricultores menos favorecidos.

Algunos efectos o consecuencias de esta postura, claramente heterodoxa, serían los siguientes: rompe con la "funcionarización" creciente de los agricultores europeos, hoy por hoy totalmente dependientes de la burocracia y del "papeleo" para cobrar sus subvenciones; pretende que el precio de referencia para el agricultor sea el interior, no el internacional, más remunerador que el segundo; y no tiene especiales inconvenientes, ...al menos para una visión crítica y en cierto modo utópica como la aquí expresada.

$* * *$

Nuestra postura se encuentra más cerca de esta última estrategia que de las anteriores, aunque somos conscientes de la dificultad de conseguir su aceptación dentro de la propia UE y fuera de ella en el marco de la OMC. Es obvio que por ahora las cosas no van por aquí, y, desde luego, el tema de la pobreza de los países del Sur no entra en la agenda de la reforma de la PAC; nos tememos que la postura que aquí defendemos difícilmente será asumida, en concreto, por los negociadores de la Comisión Europea. Sin embargo, en el deseo de "dar qué pensar" a nuestros lectores y de crear conciencia so bre los aspectos implicados, de forma sistemática, intentamos resumir los elementos de nuestra propuesta en el apartado siguiente.

\section{Una propuesta: 11 estrategias para una nueva política agraria y rural en un mundo globalizado}

A la luz de las anteriores consideraciones, proponemos una batería de once estrategias que no pretenden ser ni exhaustivas ni perfectamente sistemáticas; acompañamos el texto con algunos recuadros que permiten ilustrar algunas de las estrategias enunciadas.

Estrategia 1.- Es preciso promover reformas profundas en las políticas agrarias de la UE (y de otros países del Norte, como los Estados Unidas) que vayan en la línea de: a) renunciar por completo a las exportaciones agrarias subvencionadas; b) renunciar a un modelo básicamente exportador, de productos agrarios; c) eliminar las barreras de todo tipo (a excepción de las inevitables: sanitarias, etc.) a los productos agropecuarios brutos y elaborados del Sur, 
sin exigir a cambio un desarme similar en el Sur para los productos procedentes del Norte; d) reforzar el segundo pilar de la PAC -el paradigma ruralista- y todas las medidas conducentes a fortalecer una agricultura más preocupada por la calidad de los alimentos que por la cantidad, etc. Dicho con otras palabras, nos sumamosa la campaña de otros colectivos políticos, profesionales, ciudadanos, ONG, etc. que van en la línea de una nueva PAC que supera una mera política de status quo ${ }^{9}$. Interesa, por tanto, subrayar que las reformas de la PAC, en medio de numerosas ambigüedades, contradicciones y resistencias, van en esta dirección, pero se quedan cortas; es menester ir mucho más allá ${ }^{10}$.

\section{RECUADRO 1}

\section{La opinión de Oxfam Internacional}

\section{Propuestas de política para reformar el acuerdo sobre agricultura de la OMC (Resumen)}

$\checkmark$ Deberían eliminarse el dumping-subvenciones- y el uso de todas las formas de apoyo a la exportación.

$\checkmark$ La UE y los EEUU deberían rediseñar las políticas de apoyo interno de forma que promuevan efectivamente objetivos sociales y ambientales, sin que tengan impactos negativos en los productores de los países en desarrollo.

$\checkmark$ Las reglas de la OMC no deben socavar el derecho de los países en desarrollo a implementar políticas agrarias nacionales que promuevan el derecho a la alimentación y a un modo de vida sostenible. Esto se podría conseguir incorporando una "Caja del Desarrollo" que permitiría ampliar los tipos de intervenciones que los países en desarrollo podrían aplicar.

$\boldsymbol{V}$ Los gobiernos de los países en desarrollo deben diseñar e implemen-

9 La primera de las políticas enunciadas y analizadas en el epígrafe anterior.

10 Aquí no podemos sino mostrar nuestro acuerdo con la totalidad de los postulados de Oxfam (Recuadro 1) así como los incluidos en el decálogo de Los Verdes en el Parlamento Europeo (Recuadro 2), y prácticamente todas propuestas de Coordinación Campesina y Vía Campesina. Véase también la estrategia 9 sobre las alianzas necesarias. 
tar políticas de comercio agrario y de desarrollo rural a favor de los pobres, que promuevan la seguridad alimentaria y modos de vida sostenible.

$\checkmark$ Los países desarrollados deberían facilitar el acceso a sus mercados de las exportaciones agrarias de los países en desarrollo mediante la reducción sustancial de los aranceles generales, la eliminación de las tarifas escalonadas ${ }^{11}$, y la reducción de las barreras no arancelarias.

$\checkmark$ Los países en desarrollo deberían quedar exentos de las obligaciones mínimas de acceso a mercados de la OMC, especialmente para las materias primas alimenticias, así como disfrutar de cierta flexibilidad para alcanzar la seguridad alimentaria.

$\checkmark$ Los principales países exportadores de productos agrarios deberían establecer un fondo para ayudar a los países en desarrollo importadores de alimentos con el fin de que puedan abordar el pago de sus importaciones alimenticias y financiar programas para incrementar la productividad agrícola.

$\checkmark$ Los gobiernos deberían comenzar a aplicar un mayor control del papel de las empresas multinacionales en el comercio internacional de productos agrarios. ${ }^{12}$

$\checkmark$ Los países productores y consumidores deberían investigar, financiar e implementar esquemas conducentes a manejar la oferta y los stocks de materias primas con el objetivo de estabilizar los precios, donde ello sea posible.

Estrategia 2.- La denuncia de los efectos negativos que las políticas agrarias proteccionistas de los países ricos, en particular de la UE, tienen en la producción agraria y en las condiciones de vida del medio rural de los países menos desarrollados, no debe hacer creer que es en el mercado mundial

11 Se refierea la práctica de imponer aranceles cada vez más fuertes conforme mayor es el grado de elaboración de los productos tropicales exportados por los países en desarrollo a los países desarrollados; obviamente, los aranceles escalonados tienen por objetivo fomentar el desarrollo de las industrias transformadoras en el Norte y frenarlo en el Sur.

12 UNCTAD sería la organización mejor situada para asumir el rol de control de las actividades de las multinacionales agroalimentarias. 


\section{de bienes alimenticios donde se juega principalmente el futuro de las} agriculturas del Sur. Los estudios y la evidencia empírica disponible demuestran que ello no es así: con ser importantes dichos efectos, sólo explican en un porcentaje relativamente reducido la situación de deterioro de las zonas rurales de grandes áreas de dichos países empobrecidos. Un futuro mejor para las agriculturas y el mundo rural del Sur pasa ante todo por el incremento de las capacidades de consumo locales y regionales, es decir, por la disminución de la pobreza, lo que lleva consigo otras condiciones previas de todo tipo (macroeconómicas, como el saneamiento financiero y desaparición de la deuda externa; de buen gobierno, con el reforzamiento de la institucionalidad local y el incremento del capital social; de justicia social, con la disminución de las gigantescas desigualdades internas; de lucha directa contra la pobreza, con el establecimiento de redes de seguridad social y de cobertura de las necesidades básicas mínimas etc. etc.). (Véase recuadro 3)

\section{RECUADRO 2}

\section{0 propuestas para una nueva PAC}

\section{(Propuestas de "Los Verdes" en el Parlamento Europeo, 7 de febrero de 2001-Resumen)}

“...Es preciso que la PAC deje de oponer calidad y precio, protección del entorno y rentabilidad, competencia y garantía de rentas. En lugar de subvencionar la producción, la destrucción y la exportación de excedentes, la nueva PAC debe colocar en primer plano de las preocupaciones políticas la calidad de los productos alimenticios, la preservación de los recursos naturales, así como el desarrollo de la economía rural. La calidad de los productos agrícolas debe ser juzgada en el contexto de su campo de acción y teniendo en cuenta más allá los efectos secundarios de su proceso de producción." Estas son, telegráficamente, las 10 propuestas ${ }^{13}$ :

13 Es un mero enunciado. Cada una de las diez propuestas consta de unos párrafos de consideraciones previas sobre la problemática considerada y de unas propuestas de medidas concretas de acción y de política. Por razones de brevedad sólo transcribimos el enunciado de las 10 propuestas, remitiendo al lector interesado al texto completo (que en la versión francesa que manejamos ocupa 7 páginas). Puede consultarse la página web de los verdes en el Parlamento Europeo: «www.les-verts-europe.org> 
1. Integración del principio de precaución en la producción de bienes alimenticios.

2. Condiciones marco, ecológicas y sociales, que garanticen la calidad, necesarias para la obtención de una ayuda pública.

3. Precios agrarios y política en materia de competencia: una competencia leal en torno a la calidad.

4. Posibilidades actuales de reorientación: medidas horizontales, desarrollo rural, programas relativos al entorno agrario.

5. Distribución de medios / ampliación al Este: la crisis exige una revisión de la Agenda 2000.

6. Política encaminada a la mejora general de la calidad de los productos alimenticios y a la promoción de la agricultura biológica.

7. Control de la producción y balance proteínico: saneamiento de las tierras cultivables en lugar de barbecho.

8. Relaciones comerciales internacionales y OMC. La crisis de las vacas locas pone en cuestión el pretendido modelo agrícola europeo.

9. Control democrático y codecisión del Parlamento Europeo en la Política Agraria Común.

10. Investigación agrícola, formación, diálogo cultural entre urbanos y rurales.

Estra tegia 3.- Es preciso incentivar el estudio detallado del impacto de las políticas proteccionistas de los países del Norte, en particular de la UE, sobre la agricultura, la producción agraria, y la situación del medio rural de los países pobres. Dicho impacto no es unívoco, cla ro y general: por eso debe ser estudiado con detalle distinguiendo países (la protección agraria del Norte no afecta por igual a todos los países), productos (hay grandes diferencias según la especialización productiva de las distintas zonas y los productos afectados -por ejemplo granos básicos o productos de exportación-, no todos susceptibles de comercio exterior) y actores (agricultores grandes vs. medianos-pequeños o campesinos-finqueros, agricultores vs. empresas de transformación y comercialización, especialmente multinacionales alimentarias) en el escenario internacional del comercio agrario. 


\section{RECUADRO 3}

El desarrollo de los países pobres no se juega principalmente en los mercados exteriores

Relación entre barreras comerciales y nivel de desarrollo

\section{Una referencia de Dani Rodrik ${ }^{14}$}

"¿Menores barreras comerciales producen mayores progresos económicos? Los estudios disponibles no revelan una relación sistemática entre el nivel medio de aranceles de un país y las restricciones no arancelarias y su subsiguiente tasa de crecimiento económico. Si acaso, la evidencia para los años 90 indica una relación positiva entrelas tarifas y el crecimiento económico. La única relación sistemática es que los países desmantelan sus restricciones al comercio conforme van siendo más ricos. Esto explica el hecho de que los hoy países ricos, con pocas excepciones, se embarcaron en la senda del moderno crecimiento económico amparados por barreras proteccionistas, pero actualmente tienen bajas barreras comerciales."

Esta consideración avala nuestra tesis de que un cierto grado de protección parece necesaria en las primeras fases del proceso de desarrollo económico. El cómo de esa protección es una cuestión crucial, así como el modelo de desarrollo interno que se adopte, y cuál sea la evolución de los factores concomitantes al modelo, tan importantes o más que el propio comercio exterior a la hora de hacer que un determinado país o región entre en la senda del desarrollo.

Estrategia 4.- No hay "dos" políticas a gra rias y rurales, ra dicalmente diferentes, una para el Norte y otra para el Sur. La coherencia en los presupuestos filosóficos y éticos conducen a formular una sola propuesta, que no admita contradicciones entre los princi pios animadores de dicha política que se esgrimen para el Norte y los que se esgrimen para los países del Sur, y que tampoco admita contradicciones entre los principios que inspiran las

${ }^{14}$ Cf. Dani RodRIK.- "The developing countries' hazardous obsession with global integration". Hemos dispuesto del texto mimeografiado por cortesía de Andy Mold. Una versión de este artículo aparece en Foreign Policy, marzo/abril 2001, con el título: "Tradings in Illusions". Dani Rodrik es profesor de la Universidad de Harvard. 
distintas políticas de los países del Norte, en particular de la UE (por ejemplo, los principios de la política europea de cooperación y los de la PAC, los principios de la política de cohesión tanto en el interior de la UE, como hacia los países del Este futuros miembros, y hacia el resto de los países menos desarrollados). El modelo que se proponga para el Norte debe ser posible también en el Sur con los matices, modulaciones y ritmos que sean necesarios; la diferencia no puede venir condicionada por la falta de presupuesto en el Sur: ése es precisamente el elemento novedoso esencial de las nuevas políticas a desarrollar ${ }^{15}$.

Estrategia 5.- Para promover el desarrollo de los países del Sur no basta con reforma la PAC: hacen falta más cosas... Las propuestas de modificación de la PAC tales como la eliminación de las restituciones a la exportación de productos agrarios, la eliminación de las barreras arancelarias y no arancelarias a los productos agrarios procedentes de los países menos desarrollados, la supresión de los aranceles escalonados a los productos tropicales transformados, etc., es decir los cambios imprescindibles para que las políticas europeas (y de otros países del Norte) no supongan un "a taque frontal" a los intereses de los países del Sur, siendo necesarios no son suficientes para que éstos últimos puedan acometer con éxito la lucha por su seguridad y soberanía a limentaria y para superar los graves problemas de pobreza, atraso rural y degradación ambiental y ecológica a que se ven sometidos. Es preciso defender unas políticas agrarias y rurales a utónomas en los países del Sur que incluyan la protección selectiva y a simétrica de sus propias producciones agrarias (y no agrarias ${ }^{16} \ldots$... y la financiación de estas acciones, y las de desarrollo rural más amplias, con fondos procedentes de la cooperación internacional debidamente centralizados, organizados y controlados. (Véase Recuadro 4)

15 Véase también más arriba en el apartado 4 el modelo campesino-ciudadano de Berthelot, con el que coincidimos en gran medida.

16 Es la salvedad que hay que hacer al famoso acuerdo "Everything but arms", que mencionamos más arriba. Esta asimetría es esencial para que el modelo propuesto funcione. 


\section{RECUADRO 4}

\section{Proteger la producción de alimentos en los países del Sur}

La historia de las políticas agrarias en los países de la OCDE (en particular: UE, EEUU, J apón, Canadá etc.) es la historia de un proteccionismo descarado para sus respectivas agriculturas. Con fórmulas diversas, todos han protegido de forma muy enérgica a sus agriculturas y a sus agricultores. Esta protección ha sido posible, naturalmente, sólo en los países ricos, aquellos que podían "permitirse el lujo" de subvencionar sus agriculturas con fondos públicos. Se puede afirmar que en política agraria "protege quien puede, no quien quiere".

Por tanto, para garantizar la seguridad alimentaria en las regiones con problemas de abastecimiento es preciso proteger la producción y comercialización de los alimentos básicos de dichas regiones. Es éste un corolario de la experiencia europea.

¿Por qué un sistema que fue beneficioso para la primitiva $C E E$, que permitió la desaparición del fantasma del desabastecimiento que amenazaba al continente europeo en los lustros siguientes a la segunda guerra mundial, no habría de ser bueno para los países deficitarios, con importantes franjas de población en situación de hambre o, al menos, de infraalimentación?

Más aún, ¿por qué en los últimos años los países ricos, en particular los europeos, recomiendan a otros países la desgravación arancelaria para sus producciones agrarias y la liberalización comercial y aduanera, habiendo protegido durante décadas su agricultura precisamente con eficacísimos mecanismos de esa naturaleza?

Si hay un sistema que ha funcionado eficazmente para incentivar la producción de alimentos éste ha sido el mecanismo complejo de protección seguido en la CEE durante decenios. Existe una indudable hipocresía europea, al pretender ahora que los países en desarrollo liberalicen sus sectores productivos, incluidos los alimentos básicos. La UE sólo se ha avenido a modificar la PAC cuando no le quedaba más remedio...

¿Por qué no aplicar en los países con déficits de producción de alimentos los sistemas que tanto éxito (quizás excesivo éxito) tuvieron 
en la CEE? Ya que es impensable la financiación endógena de una tal protección, ¿sería tan disparatado plantear la constitución de un fondo similar al FEOGA con recursos financieros procedentes de la cooperación internacional para proteger a su agricultura? En otras palabras, si el problema de la seguridad alimentaria es uno de los más importantes del planeta, y las soluciones arbitradas hasta la fecha no han dado resultado ¿por qué no crear un fondo solidario mundial de protección de la alimentación? ${ }^{17}$

Estrategia 6.- No habrá una buena política agraria que no sea al mismo tiempo una buena política ruralista. En otras palabras, lo que vale para el Norte, vale para el Sur. Es preciso evitar el peligro de esta blecer una dicotomía entre las política s necesarias en el Norte (más ruralistas, dado que los países ricos ya aseguraron hace tiempo su aprovisionamiento alimenticio) y las del Sur (más agraristas y productivistas, dado que la inseguridad alimentaria y la pobreza rural son los problemas más acuciantes y urgentes que hay que resolver). No hay políticas agrarias de futuro que no sean rurales, y no hay políticas rurales que no incluyan políticas agrarias adaptadas a las condiciones de cada país o región. En cualquier caso, por muy urgente que sea el incremento de la producción y de la productividad en los países del Sur, ello no puede hacerse al precio de la degradación a mbiental, el avance de la frontera agrícola o la intensificación a base de insumos importados.

\section{Estrategia 7.- Es necesario reivindicar una serie de derechos básicos} que se encuentran debajo o detrás de las exigencias de cambios que se plantean a las vigentes políticas agrarias y de las nuevas políticas que se proponen. Estos derechos podrían resumirse en tres grandes bloques: a) el derecho básico de los agricultores y de los habitantes del mundo rural a llevar una vida digna en su medio de origen y en su lugar de trabajo; b) el derecho de los países, o mejor de los grupos de países organizados en integraciones regionales, a que se aplique a su vez el principio de cohesión a su soberanía alimentaria (que es,

17 Por otro lado, esto no es algo tan extraño. Lo que proponemos se parece bastante -y sería más eficaz para el desarrollo endógeno de los países pobres- al sistema STABEX que la UE aplica a los países de África, Caribe y Pacífico del Convenio de Lomé para estabilizar los precios y que se refiere sólo a los productos de exportación (con el consiguiente peligro de descuidar la producción de alimentos básicos) y que cuenta además con limitados recursos financieros. 
como vimos, más que seguridad alimentaria), lo que implica su derecho a asegurar el autoabastecimiento alimenticio en la medida de lo posible, a la vez que se preserva la actividad y la renta en el medio rural; c) el derecho de los ciudadanos en general (enfoque de la demanda) a exigir que el medio rural satisfaga una serie de funciones, antiguas y "nuevas" para garantizar a todos un desarrollo humano sostenible, derecho que irá acompañado del deber de retribuir adecuadamente esas nuevas funciones. Nótese que estos derechos no dependen del nivel de bienestar del país o del bloque considerado, por lo que deberán garantizarse, a la vez, para los países del Norte y para los países del Sur. ${ }^{18}$

\section{RECUADRO 5 \\ ¿"Derecho a exportar" o "derecho a producir"? La opinión del GRUPO DE SEILLAC}

Un grupo de reflexión francés (el ya hoy famoso GRUPO DE SEILLAC) ${ }^{19}$ ha expresado con particular honestidad y vigor la relación que existe entre la crisis agraria y rural de los países de la UE y el problema alimenticio mundial; citamos sus palabras textualmente:

“...El problema agrario es tan sólo uno de los aspectos de la crisis que sufre el mundo a finales del segundo milenio... Se trata de un problema condenado a no encontrar solución si no se aborda desde un enfoque coherente que tenga en cuenta el mundo entero en su complejidad creciente, en su unidad y su diversidad...

...Una reflexión ampliada a la UE, al continente europeo, a los países con amplios espacios que dominan hoy el mercado, así como a los

18 Véanse las pertinentes reflexiones del Grupo de Seillac al respecto en el Recuadro 5.

19 En diciembre de 1992 un grupo de 20 franceses de todas las tendencias reunidos en Seillac (Francia) elaboraron un manifiesto que vio la luz en abril de 1993 y que ha tenido un eco notable, por supuesto en Francia, pero también en otros contextos europeos. Forman este grupo una serie de personalidades muy conocidas, entre las que podríamos destacar a Michel DEBATISSE, Alain DELAUNOY, Bertrand HERVIEU, Louis MALASSIS, Edgar PISANI, etc. EI texto en español aparece en: Edgar PISANI (Dir.); Christian BLANC, Pierre CALAME y otros (1993), "Por una política europea de la sociedad y del espacio rural, de la investigación, de la producción y de las industrias agrarias". Revista de Estudios Agro-Sociales, no 165, julioseptiembre, pp. 177-193. 
países con espacios reducidos que se sienten preocupados por su seguridad alimentaria y por conservar sus paisajes; y también, y sobre todo, a los países del Tercer Mundo abocados, por el crecimiento demográfico y por la lenta evolución de los sistemas productivos, a la dependencia y, al mismo tiempo, al hambre, a la urbanización y a la emigración...

Nunca ha habido política agraria común, sino únicamente un conjunto de normas y mecanismos sobre el sistema productivo aislado de su contexto, dirigido hacia la autosuficiencia, incapaz de evolucionar una vez alcanzada ésta. Unos mecanismos cuyo efecto ha sido, contrariamente a lo establecido en el Tratado de Roma mismo, favorecer las explotaciones, los productos y las regiones mejor dotados... Todo ha ocurrido como si, escapando de la voluntad de quienes la diseñaron, la política común se hubiera transformado progresivamente en un instrumento de preparación de la agricultura europea para el proceso de mundialización de los intercambios. En ese sentido, ha tenido éxito, ya que ha permitido a la Comunidad conquistar cuotas de mercado que nunca había tenido. Pero también la ha expuesto a las críticas de quienes consideran que la libertad de los intercambios lleva consigo la desaparición de toda intervención pública. Al ampararse en el mercado, la política agraria común no tiene argumentos frente a los que invocan éste...

...Debe afirmarse el principio de que la seguridad alimentaria no puede ser considerada un concepto global (ya que, en conjunto, el mundo produce bastante para alimentar a todos los seres humanos) sino un objetivo nacional o regional, ya que cada país o cada continente tienen el derecho y el deber de asegurarse su alimentación...

...Un sistema en el que algunos tengan el derecho de producir en exceso, impidiendo de esa forma producir a los demás, es un sistema abocado a la ruptura...

...Si se concede preferencia -hasta el punto de convertirla en exclusiva- a la función productiva de la agricultura, si lo único que se considera significativo es el rendimiento cuantitativo, ¿no corremos el riesgo de destruir paisajes, de desordenar los territorios, de crear desequilibrios que pronto serán perniciosos? 
...Es preciso [entre otras cosas] d) Reanudar las negociaciones sobre el comercio internacional considerando, aparte del objetivo de desarrollo de los intercambios, los objetivos de seguridad alimentaria nacional o regional, el incremento de la capacidad productiva de los países en desarrollo y el mantenimiento del papel fundamental de la agricultura en los equilibrios internos sociológicos, económicos y ecológicos de todos los países considerados. Rechazar una distribución de los mercados que sólo beneficie a las potencias exportadoras. Llegar hasta el final de este cuestionamiento, preparando desde ahora la reducción progresiva, pero inevitable, de la capacidad exportadora de la Comunidad. Si ni el Sur ni el Este son capaces hoy de satisfacer sus necesidades agrarias, hay que proporcionarles los medios de supervivencia, fomentando al mismo tiempo el desarrollo de sus capacidades productivas."

Estrategia 8.- Hay que pagar en el Norte, y también en el Sur, la factura de estas políticas solidarias. Es necesario transmitir a la sociedad el mensaje de que la s políticas quese reivindica n no son indoloras, tienen un coste que habrá de ser asumido: a) ante todo, por parte de los agricultores y los ciudadanos de los países ricos, aplicando el principio de la progresividad, con el fin de liberar los recursos financieros necesarios para la aplicación eficiente de dichas políticas; pero también, b) por parte de las propias sociedades del Sur, que habrán de proceder a mejoras radicales tanto en la lucha contra la pobreza y en la disminución de las injustas y enormes desigualdades de renta y bienestar entre sus propios ciudadanos, cuanto en el fomento del buen gobierno (good governance) como condición sine qua non para el establecimiento de estas políticas de desarrollo agrario rural (y cualesquiera otras).

Estrategia 9.- Será preciso construir alianzas estra tégicas estables con las fuerzas europeas que tienen programas semejantes ${ }^{20}$. Pensamos en particular en colectivos tan variados como: algunos partidos del grupo europeo

20 Partiendo del hecho de que hay diversas posturas posibles o diversas estrategias, como les Ilama Berthelot en su excelente trabajo en Le Monde Diplomatique. Obsérvese de nuevo que la postura que defendemos se acerca sin duda más a la tercera estrategia típica definida por Berthelot, pero con aportaciones propias, que la enriquecen con una mejor visión y perspectiva de las políticas agrarias del Sur. 
"Los Verdes-Alianza Libre Europea"21 o el movimiento "Coordinación campesina europea" y su homólogo mundial "Vía campesina"; en en colectivos prestigiosos como el Grupo de Brujas o del más veterano Grupo de Seillac ${ }^{22}$; en asociaciones de consumidores, otras asociaciones de solidaridad internacional, así como en representantes de los poderes locales y regionales, etc. Estas políticas de alianzas deben también abrirse a los países del Sur y a los países del Este de Europa de próxima incorporación. Hay que convencer a los actores interesa dos de que la defensa de los intereses de los agricultores y el medio rural de los actuales y futuros miembros de la UE no puede hacerse al precio de deteriorar aún más las condiciones de vida de los rurales de los países terceros, en particular de los menos desarrollados. Casi todas las reivindicaciones de estos colectivos son asumibles, pero su gran debilidad es que no presentan una propuesta de PAC renovada que sea coherente y asumible al mismo tiempo en los países del Norte y en los países del Sur. Creemos que es preciso y es posible ir más allá de lo que casi todos dicen, e incluir en la agenda: a) la propuesta de políticas agrarias y rurales propias de los países del Sur (a ser posible por bloques regionales integrados, véase el caso centroamericano), lo que implica una campaña decidida a favor del "buen gobierno"; y b) defender la creación de una Fondo para el desarrollo bien dotado de recursos y con un componente esencial destinado a la protección de la seguridad y de la soberanía alimentaria en los países del Sur. Nos sumamos básicamente a la propuesta de CAFOD (prestigiosa organización católica británica de ayuda al desarrollo) de una "Box of development". Otra parte importante de los recursos de este Fondo se destinarían a asegurar redes de seguridad mínimas para zonas y colectivos especialmente vulnerables. Sería una especie de "Estado del bienestar" multinacional, pero no a base de acciones puntuales y desintegradas en los territorios ( al estilo de las acciones de emergencia a cargo de demasiados agentes no coordinados) sino pasando por órganos de coordinación nacionales y/ o regionales como "Programas nacionales de desarrollo rural".

Estrategia 10.- Subrayar la protección de los consumidores y del medio a mbiente del Norte. En las negociaciones de la OMC, consideramos, en primer lugar, asumible la siguiente propuesta de los Verdes en el Parlamento Europeo: "el primer objetivo de la nueva PAC consiste hoy en asegurar las condiciones para una alimentación sana y durable de los europeos, incluidos los

\footnotetext{
${ }^{21}$ Véase de nuevo el Recuadro 2 supra.

22 Véase de nuevo el Recuadro 5 supra.
} 
nuevos Estados miembros. La protección preventiva de los consumidores debe fijarse como cláusula de protección en las negociaciones agrícolas de la OMC, con el fin de evitar una repetición de la batalla relativa a las hormonas. Por otra parte, la UE debe revisar rápidamente su estrategia de negociación y centrar esta última sobre una política estructural y ambiental reforzada para el espacio rural". Por otro lado, la UE debe forzar a los países ricos exportadores de alimentos a que acepten una política común tendente a priorizar el tratamiento expuesto en la estrategia siguiente con respecto a las producciones agrarias de los países del Sur. Una posición unilateral de la UE, por muy generosa que fuera en el mejor de los casos, no serviría de nada si no va acompañada de posturas similares por parte de los grandes bloques exportadores e importadores, empezando por los EEUU.

Estrategia 11.- En esas mismas negociaciones de la OMC la UE debe defender la cláusula de asimetría en el tratamiento de las medidas proteccionistas de los países del Sur frente a los del Norte. Ello implica que la UE debe abogar por el establecimiento de una auténtica Política Agraria y Rural Común para los países del Sur (PARCS) ${ }^{23}$ en el marco de un acuerdo internacional que incluiría la creación de un Fondo para el Desarrollo dotado de medios suficientes y articulado democráticamente con representación equitativa de los países o instituciones multilaterales donantes y de los propios países beneficiarios. Esta PARCS debería incluir medidas asimétricas de protección de la producción de alimentos en el Sur, con carácter transitorio pero con periodos largos, incluyendo naturalmente cláusulas que permitan que las políticas agrarias nacionales y/ o regionales en su caso sean al mismo tiempo políticas que fomenten el desarrollo rural integrado de las zonas rurales del Sur; ese desarrollo rural integrado sólo será posible si, a escala nacional o regional, se ponen en funcionamiento mecanismos e instituciones de articulación que permitan integrar las acciones en el territorio en los diferentes ámbitos ( salud, educación, infraestructuras, formación, redes de comercialización etc.) superando el escollo actual de las acciones dispersas y desintegradas cuando no contradictorias. Es decir, es preciso que cada país o región defina un auténtico Plan Nacional o Regional de Desarrollo Rural Sostenible ${ }^{24}$.

23 Siglas que en francés equivaldrían al plural de "parque"...

24 Al estilo del que ya viene funcionando desde hace un par de años de manera relativamente exitosa en Honduras (PRONADERS: Programa Nacional de Desarrollo Rural Sostenible), o del que se intenta llevar a cabo en Nicaragua (véase más adelante, en este mismo número, la "Iniciativa para el desarrollo rural en Nicaragua", pp. 485-497). 


\section{Recapitulando}

Soñamos con una nueva política agraria y rural europea que, sin abandonar su misión de proteger el tejido social rural facilitando el cumplimiento de las múltiples funciones que la sociedad demanda al mundo rural, abra los ojos a las necesidades de los países en vías de desarrollo, en particular de sus campos y sus campesinos. En último término no se trata más que de volver a los orígenes, recuperando la inspiración de la primera PAC y, simultáneamente, incorporando la filosofía de las políticas estructurales tendentes a implantar de alguna manera un sistema de compensación interterritorial en beneficio de las zonas más desfavorecidas; pero ahora ya no a escala de los hoy 15, mañana 21 - 27 países miembros de la UE ( lo que no es poco), sino abriendo el horizonte a las zonas más desfavorecidas del planeta, cuya escandalosa precariedad se hace insufrible en un mundo tan globalizado como el nuestro. Ello implica la desaparición de todas las barreras a las importaciones de productos agrarios procedentes de los países en vías de desarrollo, la supresión de las subvenciones a las exportaciones que perjudican a dichos países, la adopción de medidas preferentes (tipo STABEX ${ }^{25}$, EBA ${ }^{26}$, etc.) con respecto al grupo de los países menos adelantados etc.

Sin embargo, no es evidente que sólo la urgente radical apertura de los mercados europeos a los productos agrarios del Sur, y la deseable desa parición de las exportaciones subvencionadas, beneficien directa y principalmente a los productores pobres de la mayoría de los PVD. Pensamos que lo que fue bueno para Europa en los 50, con las debidas correcciones, puede ser bueno para los países menos desarrollados. No es ninguna utopía soñar con un Fondo Mundial de Desarrollo Rural (en el seno de o ligado a un Fondo para el Desarrollo más global), que proponemos se transforme en una de las agencias prioritarias de la acción multilateral (quizás en el seno de un Banco Mundial más democratizado), dotado de un montante aproximado de 100.000 millones de dólares anuales ${ }^{27}$, con una doble finalidad: a) la protección asimétrica (por diversas

25 En el marco de los Acuerdos de Lomé suscritos por la UE con países de África, Caribe y Pacífico, se trata de medidas tendentes a garantizar la estabilidad de los precios de las exportaciones de dichos países hacia la UE, compensando con una financiación adecuada los eventuales descensos de las cotizaciones mundiales de dichas materias primas.

26 "Everything but arms"; véase supra nota 7.

27 Por aventurar una cifra...: es algo más del doble de lo que dedica cada año sólo la UE a proteger su propia agricultura. 
vías) de las producciones alimentarias de los países que padecen de inseguridad crónica en ese ámbito o que dependen de sus exportaciones agrarias en gran medida, y b) la promoción económica mediante acciones integradas en las zonas rurales, en donde la lucha directa contra la pobreza (en todas sus dimensiones) es una condición sine qua non para el despegue económico y la autosuficiencia alimentaria. En los correspondientes programas será preciso conceder una atención prioritaria al fortalecimiento institucional a escala supranacional (en bloques más integrados económicamente, como es el caso de Centroamérica, al que varias veces nos referimos en el presente texto), nacional y regional o local.

De todas maneras, no hay una receta universal para el desarrollo, ni una fórmula mágica que pueda ser aplicada de forma homogénea en situaciones tan dispares. No es poco que los países industrializados -y ante todo Europa, que pretende "exportar" un modelo integrador solidario y respetuoso de los derechos humanos- remuevan los obstáculos injustos que plantean sus actuales políticas financieras, económicas, comerciales y agrarias en particular; luego habrá que permitir a cada pueblo o país elaborar su propia agenda, ayudándoles si acaso a disponer de las condiciones adecuadas para ello. En último término, aun a riesgo de ser calificados de ingenuos, seguimos pensando que los países del Sur tienen que ser los protagonistas de su propio desarrollo. Pero además, el desarrollo no se puede importar: el convencimiento de que no hay desarrollo si éste no es endógeno implica la necesidad de respetar los ritmos, asumir los plazos largos, trabajar "con" y no sólo "por y para". Como declaró significativamente en cierta ocasión en una visita a España el que fuera Ministro de Economía de la India:

"El desarrollo no se puede exclusivamente importar desde fuera, aunque desde fuera se puede ayudar" 28.

Abríamos esta presentación con un hermoso texto del Popol Vuh, el conocido relato épico de los mayas quichés; según él, cuando los dioses quieren castigar a los mortales les empañan la vista para que no puedan ver sino lo que está cerca. Ojalá la reflexión que presentamos, todo lo discutible que se quiera, ayude a levantar los ojos de la hierba; sólo así podremos otear el horizonte...

28 Manmohan Singh: antiguo Ministro de Economía de India, actualmente líder de la oposición. Entrevista en El País-Negocios, 2 de octubre de 1994, p. 19. 